\title{
LA ORGANIZACIÓN DE LA ATENCIÓN SOCIOSANITARIA A LAS PERSONAS MAYORES EN EXTREMADURA
}

\author{
Celeste García Paredes y Ana Nieto Masot \\ Dpto. Arte y Ciencias del Territorio. Área de Geografía Humana. \\ Universidad de Extremadura
}

\section{RESUMEN}

En una sociedad marcada por estar inmersa en un proceso de envejecimiento latente, una adecuada organización de los recursos sociosanitarios encaminados a cubrir las necesidades de las personas mayores, es totalmente necesaria. Con este planteamiento, se revisará la distribución actual y la situación real entre la oferta y la demanda en las residencias geriátricas y en los centros de día repartidos por todo el territorio extremeño, con el fin de detectar los posibles desajustes estructurales entre el grado de envejecimiento y la oferta de servicios sociosanitarios.

Palabras Clave: servicios sociosanitarios, envejecimiento, Extremadura.

\section{ABSTRACT}

\section{The organization of health resources of elderly people in Extremadura}

In a society characterized by the presence of a rapid demographic aging, it is required an adequate organization of health resources for the purpose of meeting the needs of elderly people. With this main idea, we analyze the distribution of nursing homes and adult day care centers in Extremadura and study if the supply of nursing homes and adult day care is enough to cover the needs of dependent elderly population in our region. The purpose is to classify which is the real demand and supply in this residential care and detect possible irregularities to propose an acceptable balance between supply and demand in the health care.

Key words: health care, demographic aging, Extremadura.

\section{INTRODUCCIÓN}

\subsection{Envejecimiento y dependencia}

El aumento de la esperanza de vida entre las personas mayores inevitablemente trae consigo las palabras dependencia o atención. Es cierto, que no por ser mayor se requiere una serie de atenciones y cuidados, puesto que no todas las personas sufren un deterioro cognitivo o una pérdida de movilidad. Hay que partir de la idea de que la dependencia es un fenómeno complejo y multicausal (Sánchez, 2004), pero con el avance de los años el cuerpo humano se vuelve más frágil y vulnerable, necesitando una ayuda externa para realizar las actividades más comunes como ducharse, vestirse o incluso comer. Es aquí en donde el término "dependencia" adquiere una mayor importancia cada vez dentro del vocabulario de los encargados de la gestión en las competencias de atención a las personas mayores. Pero, ¿a qué nos referimos al utilizar dicho término?

Según el Libro Blanco de la Dependencia (IMSERSO, 2005) y siguiendo la "Recomendación relativa a la Dependencia", trabajo aprobado por el Comité de Ministros del Consejo de Europa en 1998, se define a la dependencia como "la necesidad de ayuda o asistencia importante para las actividades de la vida cotidiana". Una definición aún más precisa y ampliamente aceptada sería "un estado en el que se encuentran las personas que por razones ligadas a la falta o la pérdida de autonomía física, psíquica o intelectual tienen necesidad de asistencia y/o ayudas importantes a fin de realizar los actos corrientes de la vida diaria, y de modo particular, los referentes al cuidado personal" (Consejo de Europa, 1998).

Contacto: Celeste García Paredes: celeste@unex.es; Ana Nieto Masot: ananieto@unex.es 
Más recientemente y con la aplicación de la Ley 39/2006, de 14 de diciembre, de Promoción de la Autonomía Personal y Atención, se define la dependencia como "el estado de carácter permanente en que se encuentran las personas que, por razones derivadas de la edad, la enfermedad o la discapacidad, y ligadas a la falta o a la pérdida de autonomía física, mental, intelectual o sensorial, precisan de la atención de otra u otras personas o ayudas importantes para realizar actividades básicas de la vida diaria o, en el caso de las personas con discapacidad intelectual o enfermedad mental, de otros apoyos para su autonomía personal" (Ley 39/2006, art. 2). De acuerdo con esta Ley la valoración tiene entre sus referentes a la Clasificación Internacional del Funcionamiento, la Discapacidad y la Salud "CIF" (OMS 2001; Egea y Sarabia, 2001, 2003; Abellán e Hidalgo, 2011).

A la vista del incremento sustancial del número de personas mayores que se ha venido experimentado de una forma más evidente a partir de los años cincuenta y sesenta del siglo XX (Puyol et al., 1993; Vinuesa, 1997), la necesidad de una legislación que regulara la situación real de dependencia se hacía más ineludible. Concretamente el colectivo que alcanza edades superiores a los ochenta años se ha convertido en la actualidad en el principal demandante de una ayuda, por el debilitamiento inherente que sufre su organismo al alcanzar una edad avanzada (Díaz y Madrigal, 2007). Se convierte así la dependencia en una carga social y familiar que recae principalmente en los cuidadores informales -normalmente las hijas o el cónyuge- (Crespo y López, 2008), que demanda una regularización por parte de las Instituciones Públicas. Como en su momento la tuvieron otros servicios básicos tales como la sanidad, la educación y las pensiones, considerados hasta el momento los tres pilares básicos de una sociedad moderna. Gracias a la regularización de la dependencia, ésta se ha convertido en el cuarto pilar del estado de bienestar.

Se analiza la aplicación de la Ley 39/2006 en Extremadura por ser una zona de estudio que presenta un fuerte proceso de envejecimiento sobre todo en sus ámbitos más rurales, persistente desde comienzos de los años sesenta, como consecuencia de la emigración y de la caída de las tasas de natalidad (Nieto y Gurría, 2010). En 2010, las personas mayores de 65 años representan un 19\% del total de la población extremeña, mientras que el porcentaje de las personas mayores en los municipios rurales, con menos de 2.000 habitantes ascendía a un 27,7\% (García y Nieto, 2012), además, de ellos más del 8,8 \% son mayores de 80 años, colectivo que en la actualidad es el principal demandante de las ayudas a la dependencia. El envejecimiento es la característica dominante de la situación demográfica de los municipios extremeños, sobre todo los que presentan mayor grado de ruralidad, y por ello, serán zonas susceptibles para estudiar la aplicación de dicha Ley.

\subsection{La atención a los mayores en Extremadura}

En Extremadura para aplicar las ayudas de la Ley 39/2006 se creó un Sistema para la Autonomía y Atención a la Dependencia, con la participación de todas las Administraciones Públicas. Dicho Sistema debe responder a una acción coordinada y cooperativa de la Administración General del Estado y las CCAA, que contemplará medidas en todas las áreas que afectan a las personas en situación de dependencia. En el caso de nuestra Comunidad Autónoma, Extremadura, el servicio que pretende garantizar unos servicios mínimos y básicos para todos los ciudadanos se denomina Servicio Extremeño de Promoción de la Autonomía y Atención a la Dependencia (a partir de ahora SEPAD), gestionado por la Consejería de Salud y Política Social del Gobierno de Extremadura. Este Servicio nace no solo como herramienta para una mejor gestión, sino como garantía para la correcta prestación de los servicios.

La estructura básica territorial empleada para la implantación de la Ley se centra en la vertebración del territorio extremeño en veinte Zonas Sociosanitarias. Estas subdivisiones se crearon como fruto de la confluencia aproximada de una o varias zonas básicas de salud del sistema sanitario, con el fin de facilitar las relaciones y los servicios entre lo "sanitario" y lo "social" (Leichsenring, 2005). Del total de estas veinte Zonas Sociosanitarias, doce pertenecen a la provincia de Badajoz y las ocho restantes a la provincia de Cáceres. Estas Zonas Sociosanitarias tienen su propia Cabecera de la Zona, aunque en algunos casos como en Vegas Bajas-Sierra de Alburquerque, Campiña Sur, Vegas Altas y Sierra de San Pedro se han creado dos Cabeceras por Zona, y por ello, en total se han establecido un total de 24 Cabeceras Sociosanitarias (Figura 1). Con la delimitación de estas Zonas, el territorio extremeño está en la actualidad diseñado para que se aplique la Ley de Dependencia en todos los espacios extremeños, tanto rurales como urbanos. 
Figura 1. Zonas Sociosanitarias de Extremadura

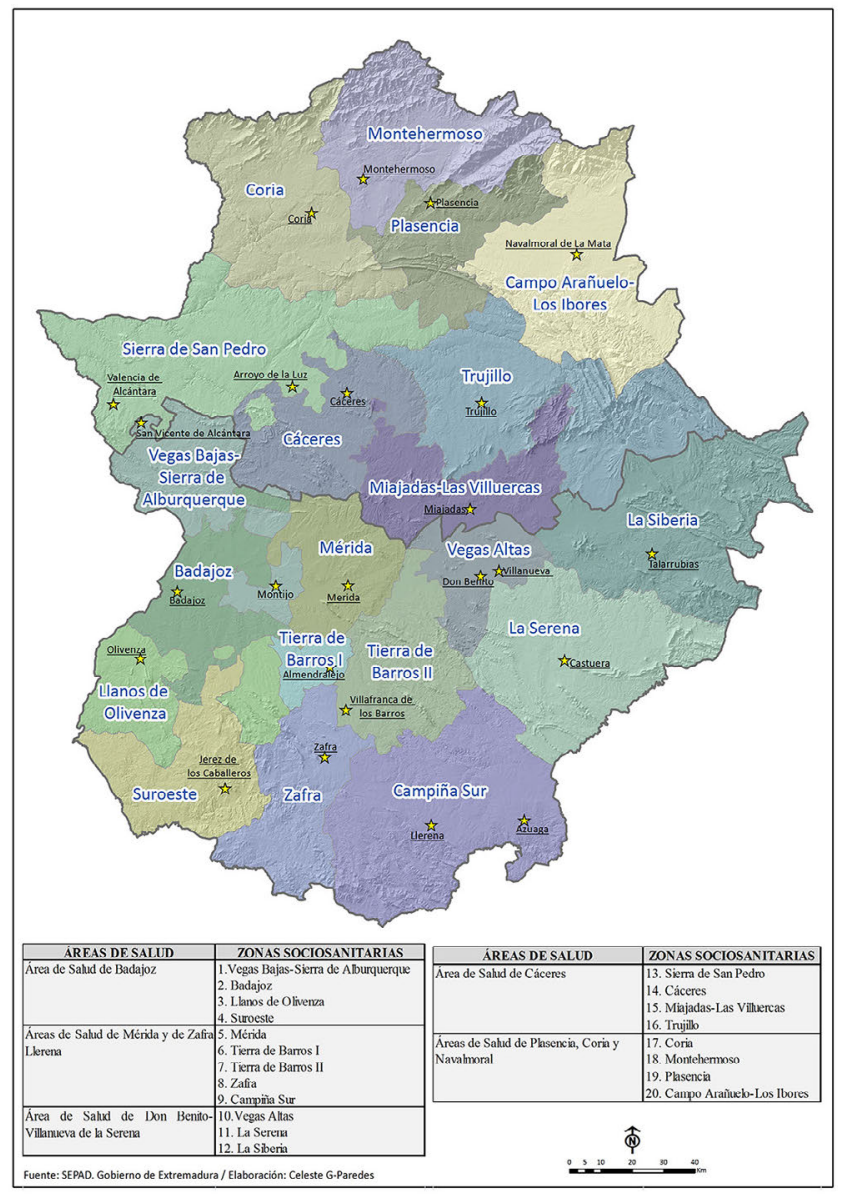

Fuente: SEPAD. Elaboración propia.

Los Equipos de Valoración del SEPAD se encuentran repartidos equitativamente en función de los habitantes de cada Zona Sociosanitaria. La sede desde donde estos profesionales prestan sus servicios se ubican en las cabeceras de dichas Zonas.

La función de estos equipos es primordial, ya que a partir del grado de dependencia que asignen a las personas, éstas accederán o tendrán derecho a uno de los servicios y/o prestaciones del Catálogo del Sistema para la Autonomía y Atención a la Dependencia (SAAD) de la Comunidad Autónoma de Extremadura. Para medir el grado de dependencia los equipos emplean un baremo ${ }^{1}$ con el que valoran la capacidad de la persona para llevar a cabo por sí misma las actividades básicas de la vida diaria (en adelante, ABVD). La valoración final emitida por el equipo de valoración determina el grado y nivel de dependencia que le corresponde a la persona. Los distintos grados de dependencia que se establecen en el artículo 26 de la Ley 39/2006 son:

a. Grado I (dependencia moderada): cuando la persona necesita ayuda para realizar varias ABVD al menos una vez al día o tiene necesidades de apoyo intermitente o limitado para su autonomía personal.

1 El Baremo de Valoración a la Dependencia (BVD), se aprobó por Real Decreto 504/2007, de 20 de abril. El BVD sirve para establecer la valoración del grado y niveles de dependencia de acuerdo con la Ley 39/2006, de 14 de diciembre. El Grado I, dependencia moderada, se corresponde con una puntuación final del BVD de 25 a 49 puntos (Nivel 1 de 25 a 39 puntos y Nivel 2 de 40 a 49 puntos). El Grado II, dependencia severa, se corresponde con una puntuación final del BVD de 50 a 74 puntos (Nivel 1 de 50 a 64 puntos y Nivel 2 de 65 a 74 puntos). El Grado III, gran dependencia, se corresponde con una puntuación final del BVD de 75 a 100 puntos (Nivel 1 de 75 a 89 puntos y Nivel 2 de 90 a 100 puntos). Asimismo el BVD permite identificar los dos niveles de cada grado en función de la autonomía personal y de la intensidad del cuidado que requiere de acuerdo con lo establecido en el apartado 2 del artículo 26 de la citada Ley 36/2006 (Ministerio de Trabajo y Asuntos Sociales, 2007). 
b. Grado II (dependencia severa): Cuando la persona necesita ayuda para realizar varias ABVD dos o tres veces al día pero no requiere el apoyo permanente de un cuidador, o tiene necesidades de apoyo extenso para su autonomía personal.

c. Grado III (gran dependencia): cuando la persona necesita ayuda para realizar varias ABVD varias veces al día y, por su pérdida total de autonomía física, mental, intelectual o sensorial necesita el apoyo indispensable y continuo de otra persona, o tiene necesidades de apoyo generalizado para su autonomía personal.

A fecha 1 de mayo de 2012 y según los últimos datos publicados por el Servicio de Estadísticas de la Subdirección General Adjunta de Valoración, Calidad y Evaluación del SAAD-IMSERSO, el número de solicitudes recibidas en la región extremeña ascendían hasta 45.525, no llegando ni a suponer el $3 \%$ del total de las solicitudes recibidas a nivel nacional. El dato más interesante es que si se relaciona este número de solicitudes con el número de habitantes de la Comunidad Autónoma de Extremadura, el porcentaje asciende hasta un 4,1\%, superando a la media nacional situada en un 3,4\%, lo que indica que en nuestra región se registra un mayor número de personas dependientes que han solicitado una valoración para que le sea asignado un servicio o apoyo, una muestra del sobreenvejecimiento que presenta nuestra región.

Del total de las 45.525 solicitudes presentadas desde la implantación de la Ley 38/2006, se han emitido un total de 41.115 dictámenes, lo que representa el 90,3\% de las solicitudes. Estos dictámenes se han clasificado según los distintos grados de dependencia recogidos en el artículo 26 de la citada Ley, mencionados anteriormente. Siendo el Grado III el que mayor número de dictámenes registra con 12.227 (lo que supone un 29,7 \% del total de dictámenes), seguido del Grado II con un total de 10.951 dictámenes (un $26,6 \%$ del total) y por último, el Grado I con un total de 10.753 dictámenes ( $26,2 \%$ del total). El volumen más numeroso de dictámenes se corresponde con las personas que están valoradas en el grado de gran dependencia, siendo éstas las que van a requerir una mayor atención, bien sea con el apoyo continuo de una persona o bien con su ingreso en un centro geriátrico.

Una vez que los demandantes ya están valorados y se les ha asignado su grado de dependencia, el paso siguiente es que dicha persona se beneficie de la cartera de servicios de atención sociosanitaria que su Comunidad Autónoma preste. En nuestra región contamos con el Catálogo del Sistema para la Autonomía y Atención a la Dependencia de la Comunidad Autónoma de Extremadura (en adelante SAAD), especificados en el artículo 15 de la Ley 39/2006 y en la Orden de 13 de Mayo de 2011². Este Catálogo servirá de base para fijar los distintos recursos sociosanitarios que deben implantarse en nuestra región. En el capítulo II de dicha Orden se recoge la amplia gama de servicios de la que dispone Extremadura: Teleasistencia, los Servicios de Promoción de la Autonomía Personal, el Servicio de Prevención de Situaciones de Dependencia, el Servicio de Ayuda a Domicilio, los Servicios de Centros de día o de Noche y el Servicio de Atención Residencial. Estos servicios tienen carácter prioritario y se prestarán a través de la oferta pública de la Red de Servicios Sociales de la Comunidad Autónoma de Extremadura, mediante centros y servicios públicos o privados concertados debidamente acreditados. La finalidad de esta amplia gama de servicios es cubrir las necesidades que la persona mayor dependiente demande. Asimismo, lo que se busca es la mayor adecuación entre las necesidades que presente la persona dependiente y el servicio que reciba. Es decir, si una persona ha sido valorada con un grado de dependencia moderada no tiene por qué estar ingresada en un centro geriátrico, sino que probablemente con una ayuda a domicilio o con acudir a un centro de día, sus necesidades estarían cubiertas.

En el siguiente Cuadro, se muestra el número y tipo de prestación que están percibiendo los solicitantes de una ayuda a la dependencia a fecha de 1 de mayo de 2012 en nuestra región. Un resumen breve de la situación real sería que de los 41.115 dictámenes emitidos, el volumen total de prestaciones percibidas asciende a 19.698, lo que viene a significar que el 48 \% de los dictámenes están financiados. Si analizamos los datos por orden descendente, son las prestaciones económicas para los cuidados en el entorno familiar y apoyo a cuidadores no profesionales las que ostentan la primera posición, con casi la mitad del total de las prestaciones, exactamente 8.938 , lo que representa un 45,3\% del total. Con este tipo de prestación la persona en situación de dependencia estará atendida por cuidadores no profesionales de su entorno (artículo 14, de la Orden de 13 de mayo de 2011). Es decir, en nuestra comunidad se sigue optando por el cuidado informal, el cuidador principal de la persona mayor sigue siendo un pariente directo,

2 ORDEN de 13 de mayo de 2011 por la que se establece el catálogo de servicios y prestaciones económicas del Sistema para la Autonomía y Atención a la Dependencia en la Comunidad Autónoma de Extremadura, la intensidad de los servicios y el régimen de compatibilidades aplicables (DOE nº 95, 19 de mayo de 2011). 
normalmente el cónyuge o un familiar que ostente hasta el tercer grado de consanguinidad o afinidad, principalmente, la hija o el hijo.

Cuadro 1. Tipo de prestaciones percibidas, situación a 1 de mayo de 2012.

\begin{tabular}{|l|c|c|c|c|}
\cline { 2 - 5 } \multicolumn{1}{c|}{} & \multicolumn{2}{c|}{ Extremadura } & \multicolumn{2}{c|}{ España } \\
\cline { 2 - 5 } \multicolumn{1}{c|}{} & Total & Porcentaje & Total & $\%$ \\
\hline Total Prestaciones Económicas & 19.698 & 100 & 946.075 & 100 \\
\hline Cuidados Familiares & 8.938 & 45,38 & 428.899 & 45,33 \\
\hline Vinculada Servicio & 5.477 & 27,80 & 61.758 & 6,53 \\
\hline Atención Residencial & 3.213 & 16,31 & 122.663 & 12,97 \\
\hline Centros de día/Noche & 741 & 3,76 & 61.971 & 6,55 \\
\hline Ayuda a Domicilio & 616 & 3,13 & 120.904 & 12,78 \\
\hline $\begin{array}{l}\text { Prevención Dependencia y promoción } \\
\text { de la Autonomía Personal }\end{array}$ & 379 & 1,92 & 18.726 & 1,98 \\
\hline Teleasistencia & 355 & 1,80 & 130.290 & 13,77 \\
\hline Asistencia de Personal & 0 & 0,00 & 864 & 0,09 \\
\hline
\end{tabular}

Fuente: SAAD-IMSERSO, Servicio de Estadísticas de la Subdirección General Adjunta de Valoración, Calidad y Evaluación.

En segundo lugar, el tipo de prestaciones más frecuentes son las prestaciones económicas vinculadas al servicio. Se financia esta ayuda cuando no sea posible la atención a través de los servicios públicos o concertados de la Red de Servicios Sociales de la Comunidad Autónoma de Extremadura y el cuidador profesional que se contrate no podrá ser cónyuge, convivir, ni tener una relación de parentesco hasta el tercer grado por consanguinidad o afinidad con la persona en situación de dependencia. Este tipo de prestación representa casi el 28 \% del total de las prestaciones en nuestra Comunidad Autónoma, que sumada a la anterior prestación económica para los cuidados en el entorno familiar, representan entre ambas un $73 \%$ del total de las prestaciones.

Le sigue en tercera posición la atención residencial que con un total de 3.213 beneficiarios, representa el 16,3 \% del total de las prestaciones. Este tipo de servicio se presta en centros residenciales, públicos o acreditados, donde el interesado recibe un apoyo integral, una atención personalizada las 24 horas del día, una atención tanto sanitaria como social. Junto a los dos anteriores, suponen un 89,4 \% del total de las prestaciones.

El resto de prestaciones, como son los centros de día y noche, la ayuda a domicilio, la prevención a la dependencia y la promoción a la autonomía personal y la teleasistencia, apenas representan el $10 \%$ del total. También a nivel nacional las ayudas para los cuidados en el entorno familiar son a las que mayores recursos económicos se destinan, aunque en este caso el segundo lugar se asigna a la teleasistencia, seguida de la atención residencial y la ayuda a domicilio.

En el texto legislativo de la Ley de la Ayuda a la Dependencia se contemplaba que la prestación a los cuidados en el entorno familiar tenía que ser una excepción. En cambio, se ha convertido en lo más común, como indica ese altísimo porcentaje de prestaciones que se conceden a los familiares directos que cuidan de los dependientes tanto en Extremadura como en España, con el 45,38 \% y 45,33 \% respectivamente. Desde el Gobierno Central se está fomentando el cambiar esta tendencia, a través de la aprobación de un nuevo Real Decreto, donde se revisarán las prestaciones económicas para cuidados en entorno familiar (Resolución de 13 de julio de $2012^{3}$ ). Se endurecen, además, los requisitos para acceder a estas ayudas: los solicitantes tendrán que demostrar que su horario laboral es compatible con el cuidado de esta persona dependiente, convivir con él, pasar un seguimiento por parte de las Administraciones y tener la formación adecuada para atender las necesidades del mismo. En caso de carecerla, tendrá que recibir los conocimientos necesarios si quiere tener a su familiar en casa. Otra de las reformas que se contemplan en esta Resolución es la modificación de la actual estructura de grados y niveles para la determinación de la dependencia. La nueva estructura pasará a tener una única división en 3 grados (Grado III: gran dependencia, Grado II: dependencia severa y Grado I: dependencia moderada) desapareciendo la división

3 Resolución de 13 de julio de 2012, de la Secretaría de Estado de Servicios Sociales e Igualdad, por la que se publica el Acuerdo del Consejo Territorial del Sistema para la Autonomía y Atención a la Dependencia para la mejora del sistema para la autonomía y atención a la dependencia, publicada en el BOE nº 185, de 3 de agosto de 2012. 
anterior en niveles 1 y 2. También, se establecerá un copago, incluidos los dependientes con discapacidad, en función de los ingresos de cada usuario.

Otro de los datos que más interesa conocer a la sociedad es la ratio de prestaciones por persona, es decir el número de prestaciones que recibe un dependiente. Pues bien, a fecha de 1 de mayo de 2012, la ratio de prestación por persona en Extremadura es de un 1,06 (Servicio de Estadística de la Subdirección General Adjunta de Valoración, Calidad y Evaluación). Esto viene a significar que las personas dependientes reciben más de un servicio, por ejemplo pueden estar recibiendo ayudas a domicilio y teleasistencia, lo que nos viene a demostrar que es un sistema complementario. Dicha ratio de prestaciones por persona es mínimamente inferior a la media nacional, un 1,24, y como aspecto a destacar positivamente, todas las CCAA ostentaban una ratio de prestación por persona superior a 1.

\section{OBJETIVOS}

En este trabajo de investigación se plantea un objetivo principal basado en el análisis de la distribución de dos recursos sociosanitarios básicos para la atención a la dependencia en Extremadura como son las residencias geriátricas y los centros de día. Esta elección obedece a la necesidad de tener un conocimiento más amplio de los cuidados comúnmente denominados como formales y reglados, que además son los que la Administración debería reforzar, habida cuenta del avance imparable del proceso de envejecimiento, especialmente de los octogenarios, posibles usuarios potenciales de este tipo de recursos sociosanitarios formales. La Administración pretende incrementar el porcentaje de receptores de la ayuda a la dependencia en este tipo de servicios y conseguir una reducción de las mismas a los cuidados en domicilio por parte de los familiares, comúnmente denominado como cuidados familiares. Hay que tener en cuenta que la intención es reglar todo el tipo de cuidados que recibe el dependiente en su domicilio, por ello, sería más conveniente apostar por las ayudas vinculadas a los servicios, la atención residencial y los centros de día. Estos dos tipos de ayudas suponen casi el $20 \%$ del total de las prestaciones percibidas en nuestra región y ofrecen una mejor asistencia a los dependientes por ser una ayuda de personal especializado del SEPAD -médicos, enfermeros, psicólogos, graduados en atención social,...-.

Se han introducido variables como el número de residencias geriátricas y centros de atención diurna por Zonas Sociosanitarias, el número de plazas ofertadas en cada centro (existen distintas tipologías desde grandes residencias con una oferta superior a las 500 plazas y localizadas normalmente en núcleos más poblados o en su radio de desplazamiento a ellos de 20-30 minutos y otros tipos de centros más pequeños y que cubren la oferta de zonas rurales menos pobladas y aisladas), el tipo de entidad del recurso sociosanitario: público o privado y, el grado de envejecimiento de estos territorios, porque la principal finalidad será analizar si existe un ajuste óptimo, adecuado, entre la oferta y demanda de estos recursos sociosanitarios.

\section{ANÁLISIS DE LA OFERTA Y LA DEMANDA DE PLAZAS EN LAS RESIDENCIAS GERIÁTRICAS}

Comenzando en nuestro estudio con la cobertura de residencias geriátricas, la región extremeña en el año 2010 contaba con un total de 229 residencias ubicadas en 162 municipios (SEPAD, 2012). En cuanto al carácter de dichas residencias destaca el $67 \%$ de la oferta residencial de titularidad pública frente a un $33 \%$ que es privada, quedando patente el dominio de la oferta pública frente a una escasa oferta privada en la atención residencial.

Una de las metas que se persigue en este artículo es determinar la cobertura real que existe en la prestación de la atención sociosanitaria, por ello, utilizar solamente el número de residencias geriátricas sería poco representativo, y así hemos ampliado nuestro análisis añadiendo la relación existente entre el número de plazas disponibles en las residencias y el número de personas mayores de 65 años, que son los verdaderos demandantes de este servicio (Rojo et al., 2007). Con este fin se ha calculado un índice muy extendido denominado "cobertura residencial" (Camacho et al., 2008) que relaciona el número de plazas en las residencias públicas y privadas con las personas mayores de 65 años.

De tal forma que la cobertura residencial media para la región extremeña en el 2009 fue de 5,17\%, lo que indica que había una media de 5,17 plazas en residencias por cada 100 mayores de 65 años. Para conocer la situación general a nivel nacional y del resto de las CCAA en cuanto a su índice de cobertura, se ha consultado el último informe elaborado por el IMSERSO sobre los servicios sociales para las perso- 
nas mayores de España ${ }^{4}$. En dicho informe se plasma que para el año 2009 el índice de cobertura de las plazas residenciales se situaba en torno al 4,43\%. Castilla y León junto a Castilla-La Mancha alcanzaron los índices de cobertura más elevados, con un 7,03 \% y un 6,5\% respectivamente, regiones que presentan además un alto porcentaje de población mayor de 65 años. Extremadura ocupaba la sexta posición, con este índice del 5,17\% y las últimas posiciones las ocupaban Murcia, Galicia y Ceuta, que no superaban un $3 \%$. Nuestra región ocupa pues una situación ventajosa con respecto al resto de CCAA, incluso supera la media nacional, ofertando un mayor número de plazas para el conjunto de la población dependiente.

Avanzando en el análisis se pretende comprobar si dentro de la ordenación territorial de la cobertura sanitaria se reproducen los mismos datos que con las medias regionales. Si se tiene en cuenta la baja densidad de población de nuestra región, debido a la gran extensión de su superficie y la escasa población que la ocupa (Nieto y Gurría, 2010), para analizar la distribución de los recursos sociosanitarios la escala territorial más adecuada son las Zonas Sociosanitarias, ya que los municipios con un tamaño medio ejercen de cabeceras comarcales prestadoras de servicios a los núcleos con una entidad menor (Minguela, 2010; Rodríguez, 2002). Esto significa que, por ejemplo, si una residencia oferta un número de plazas concreto, esa oferta no se va a ceñir solamente a su municipio, sino que personas que habiten en un municipio cercano y que no dispongan de una residencia geriátrica acudirán al que se encuentre más cercano y preste este servicio (Rodríguez, 2004). Nos permite matizar la ratio de cobertura residencial al incrementar el número de posibles demandantes.

En la Figura 2 se observa como están repartidas las 229 residencias existentes en el territorio extremeño. Se podría analizar el número de centros por Zona Sociosanitaria, pero no es un dato que nos indique con exactitud la oferta de cobertura de residencias geriátricas, debido a las diferentes tipologías en cuanto al número de plazas ofertadas de los distintos centros. Se han detectado zonas con gran número de residencias como Coria, Miajadas-Las Villuercas o Zafra que después no ofrecen gran número de plazas en residencias geriátricas, por lo que su índice de cobertura puede ser menor por dominar residencias de tamaño pequeño.

Figura 2. Total de residencias geriátricas y plazas por Zonas Sociosanitarias

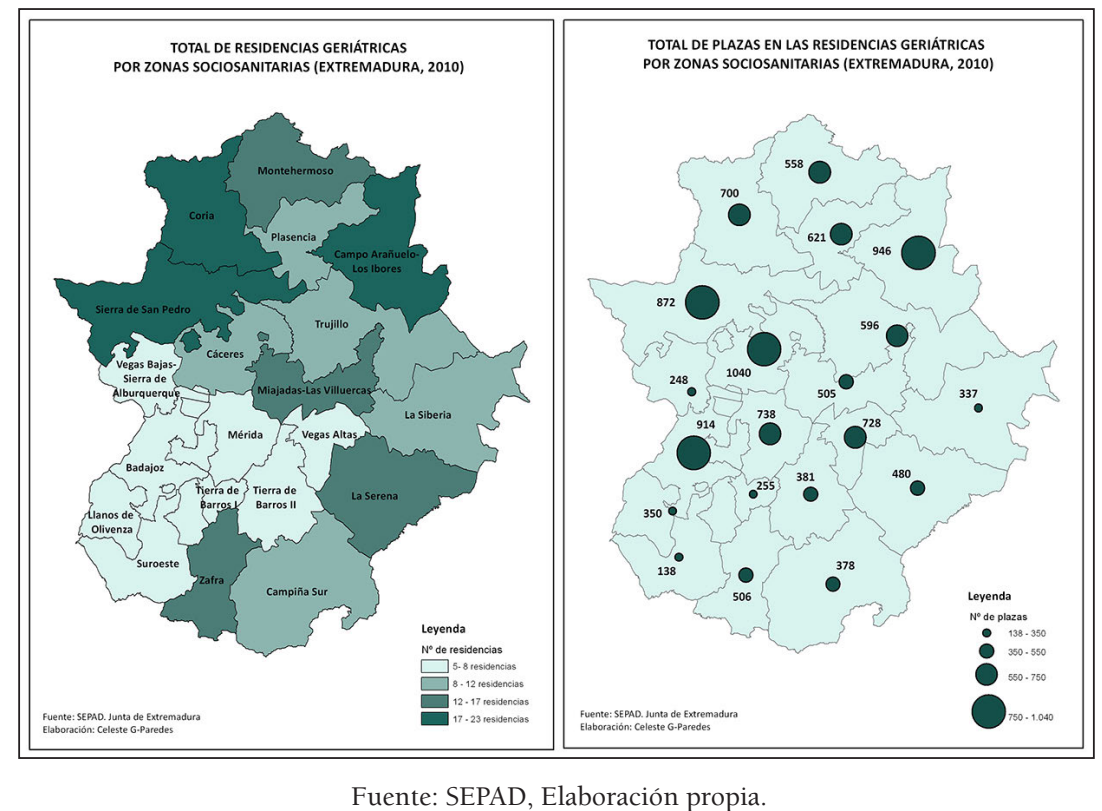

Si se tiene en cuenta el número de plazas que ofertan estas residencias, la zona con un mayor número de plazas en residencias geriátricas es Cáceres, con un total de 1.040 plazas, cuando ocupaba la undécima posición en cuanto al número de residencias. La segunda con un mayor número de plazas es Campo Arañuelo-Los Ibores (con 946 plazas), esta zona sí estaba entre las que albergan un mayor número de residencias, concretamente ocupa la tercera posición. Aparece Badajoz en la tercera posición ofertando

4 Castejón Villarejo, P. et. al. (2009): Los servicios sociales para las personas mayores de España, Enero de 2009. Perfiles y Tendencias: boletín sobre envejecimiento, $\mathrm{n}^{\circ} 43,46 \mathrm{pp}$. Edita: Ministerio de Sanidad y Política Social, IMSERSO. 
un mayor número de plazas, a pesar de contar con tan solo 7 residencias. Y por último, está Sierra de San Pedro que con sus 872 plazas cierra la lista de las zonas con una mayor oferta de plazas en las residencias geriátricas. En las últimas posiciones de la lista -con una oferta inferior a 350 plazas- nos encontramos a La Siberia, Tierra de Barros I, Vegas Bajas-Sierra de Alburquerque y Suroeste, que con sus 138 plazas es la zona con la más baja oferta (Figura 2).

En cuanto a la distribución de las residencias teniendo en cuenta el carácter de su titularidad, se aprecian ciertos detalles interesantes. La mayor oferta de residencias de titularidad pública, es decir, en los territorios en donde la Administración Central ha apostado más por la implantación de residencias públicas son Sierra de San Pedro, Coria, Montehermoso y Campo Arañuelo-Los Ibores, que son justo las zonas que registraban un mayor número de residencias geriátricas totales (García y Nieto, 2013). Ahora bien, el predominio de residencias de titularidad privada frente a la pública recaen justo en las áreas más pobladas y desarrolladas económicamente, como son Cáceres -con 8 residencias privadas frente a 2 residencias públicas-, Badajoz -6 residencias privadas frente a 1 pública-, Mérida -4 residencias privadas frente a 2 públicas- y Tierra de Barros I -3 residencias privadas frente a 2 públicas-. Asimismo, también destacan Campo Arañuelo-Los Ibores y la zona de Coria con una fuerte inversión privada, con un total de 7 y 6 residencias privadas respectivamente (Figura 3). Badajoz encabeza la lista de las zonas que ofertan un mayor número de plazas en residencias privadas, con un total de 734, seguida de Campo Arañuelo, Cáceres y Mérida. Si tenemos en cuenta la oferta pública las dos zonas que ofertan un mayor número de plazas son Sierra de San Pedro y Cáceres, con 574 y 524 respectivamente.

Figura 3. Residencias Geriátricas y número de plazas por titularidad en las Zonas Sociosanitarias de Extremadura.

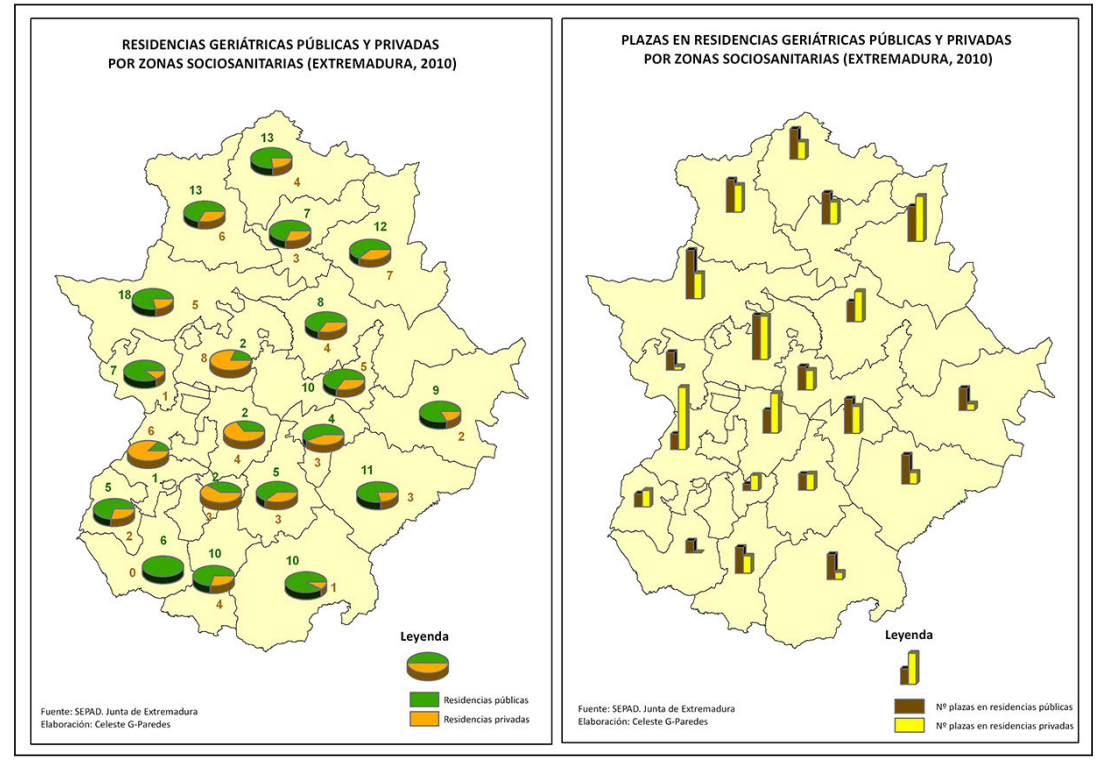

Fuente: SEPAD, Elaboración propia.

Una vez se ha realizado el estudio de la distribución y tipología -número de plazas que ofertan- de las residencias geriátricas por todo el territorio extremeño, el siguiente objetivo que se propone es detectar si existe una adecuación entre la oferta y la demanda de este recurso sociosanitario. Para analizar la oferta, se ha utilizado el Índice de Cobertura -relación entre el número total de plazas en residencias y la población mayor- por zonas sociosanitarias y se han establecido niveles con zonas que están por encima de la media -5,3\% en el 2013-: unas denominadas "muy por encima de la media regional" -con valores que están entre un 7 \% y un 8,8 \%- localizadas todas ellas en la provincia de Cáceres en zonas como: Cáceres, Trujillo, Campo Arañuelo y Sierra de San Pedro; y las siguientes, "por encima de la media regional" -con valores entre un 5,3\% y un 7 \%- localizadas en zonas de la provincia cacereña, como Coria, Plasencia y Miajadas y en la provincia de Badajoz: Olivenza, Vegas Altas, Mérida y Tierra de Barros I. Por último, las otras dos categorías establecidas indican que la cobertura residencial está por debajo de la media regional, todas ellas situadas en la provincia de Badajoz y una en Cáceres (Montehermorso), destacando por sus bajos índices de cobertura, con valores inferiores al 3 \%, Suroeste y Vegas Bajas-Sierra de Alburquerque (Figura 4). 
Figura 4. Índice de Cobertura Residencial y Grado de Envejecimiento por Zonas Sociosanitarias.

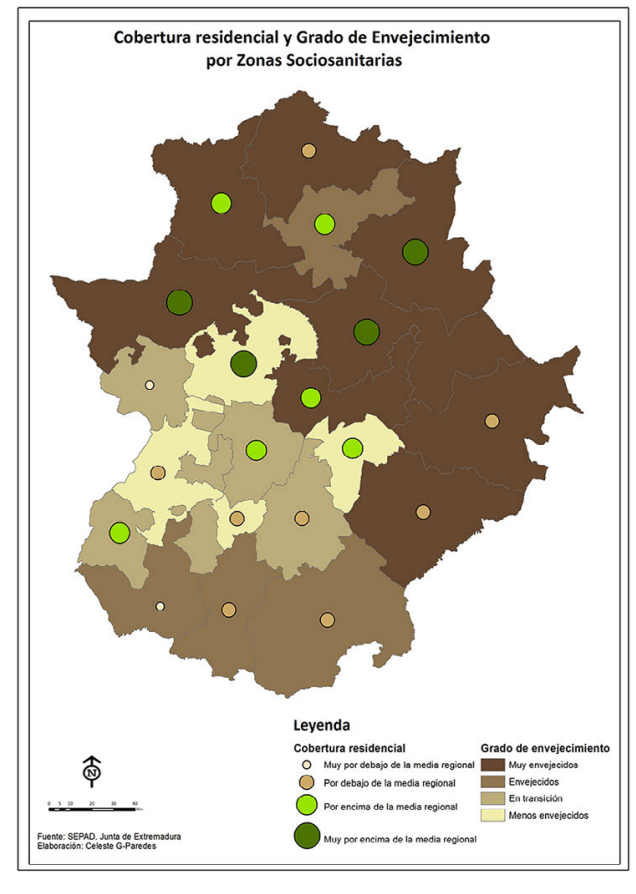

Fuente: SEPAD.

Por otro lado, la mayor dificultad en nuestro estudio era determinar qué variable utilizar para analizar la demanda, porque en el proceso de envejecimiento demográfico intervienen muchas variables demográficas: tanto variables naturales como migratorias, el comportamiento de la fecundidad, la esperanza de vida, etc (Abellán, 2000; Cachón, 1992) o simplemente se podría haber empleado la tasa de ingreso de las personas mayores en las residencias geriátricas y centros de día. Es una variable difícil de determinar y existen diferentes trabajos que utilizan las anteriormente descritas según los planteamientos del análisis. En nuestro estudio, se decidió emplear el índice de envejecimiento, por ser la variable más representativa para indicarnos el grado real de envejecimiento, -es la ratio entre el colectivo de mayores y el grupo de menores- y nos indicaban los usuarios potenciales que podrían demandar una ayuda a la dependencia. En base a la media regional, un índice de envejecimiento del $131 \%$ para el año 2010, se han determinado cuatro niveles dependiendo de este índice, por orden descendente: muy envejecidos, envejecidos, en transición y menos envejecidos, siendo las siguientes (Figura 5):

1. Zonas muy envejecidas: engloba a las que tienen un índice de envejecimiento superior a un $190 \%$. Se han detectado ocho Zonas Sociosanitarias muy envejecidas que son, por orden descendente: Trujillo (es la zonas más envejecida de las 20, con un índice de un 245,2 \%), Montehermoso, La Siberia, Sierra de San Pedro, Miajadas-Las Villuercas, Coria, La Serena y Campo Arañuelo-Los Ibores.

2. Zonas envejecidas: son aquellas zonas con valores comprendidos entre $189 \%$ y $124 \%$ y se corresponden con cuatro: Campiña Sur, Suroeste, Zafra y Plasencia.

3. Zonas en transición: zonas con valores comprendidos entre $125 \%$ y $100 \%$ siendo otras cuatro: Tierra de Barros II, Vegas Bajas-Sierra de Alburquerque, Llanos de Olivenza y Mérida.

4. Zonas menos envejecidas: con valores inferiores al $100 \%$ y coincidiendo con Vegas Altas, Cáceres, Tierra de Barros I y Badajoz (es la Zona menos envejecida de toda la región, con un índice de envejecimiento de un $82 \%$ ).

Se comprueba que las zonas más envejecidas de nuestra región se ubican en la provincia de Cáceres -excepto la zona del municipio de Cáceres que aparece como zona menos envejecida- y en el este de la provincia de Badajoz, tratándose de zonas más montañosas -Las Villuercas, Hurdes, Sierra de Gata, La Vera, el Jerte, Sierra de San Pedro y Montánchez- y periféricas de la región -La Siberia, y La Serena-. Mientras que en el oeste de la provincia de Badajoz predominan las zonas en transición y menos envejecidas, que dibujan un arco perfecto que tienen como puntos de referencia las ciudades más pobladas de la provincia de Badajoz. Son áreas de montaña y penillanura, tradicionalmente de las menos desarrolladas económicamente de nuestra región y debido a ese atraso, que se ha mantenido en las últimas décadas, han ido 
perdiendo población joven que emigra hacía las zonas más desarrolladas de Extremadura como son las zonas del regadío, de tierras de secano productivas -Tierra de Barros y su eje de prolongación hacía el Sur con las zonas de Zafra y Jerez- y las localizadas alrededor de los principales ejes de comunicación de la región -Autovía de Madrid y Autovía de la Plata- (Nieto y Gurría, 2008).

El resultado de aunar ambas variables es la obtención de un nuevo mapa denominado "Nivel de adecuación" donde se relaciona el grado de envejecimiento y el índice de cobertura residencial. Se detectan zonas que adecuan su oferta de cobertura residencial a la demanda de su población potencial -con menor o mayor grado de envejecimiento) y zonas donde no se cubre esa demanda potencial de servicios geriátricos (su índice de cobertura es muy bajo respecto a su población envejecida-. La tipología de zonas la podemos agrupar en 4 clases (Figura 5):

Figura 5. Nivel de adecuación entre la oferta y la demanda en Residencias Geriátricas

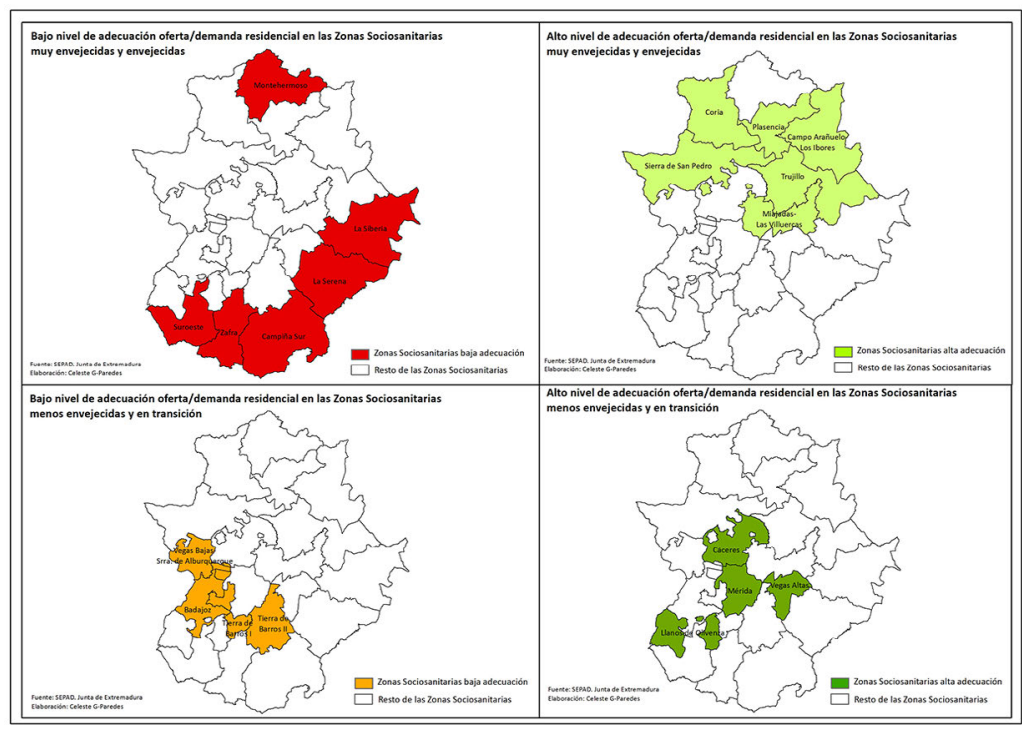

Fuente: SEPAD, Elaboración propia.

1. Zonas Sociosanitarias muy envejecidas y envejecidas con un bajo grado de adecuación entre la oferta y la demanda en residencias geriátricas. Son territorios que padecen un fuerte envejecimiento demográfico y a la vez brindan una oferta en las residencias geriátricas que no es suficiente para cubrir la posible demanda, por lo que el grado de adecuación entre la oferta y la demanda es bajo. Este grupo está conformado por seis zonas, de las que solamente una pertenece a la provincia de Cáceres (Montehermoso), y el resto se ubican en la provincia de Badajoz, de este a oeste: La Siberia, La Serena, Campiña Sur, Zafra y Suroeste. Se trata de las zonas periféricas de la provincia de Badajoz y que limitan con otras CCAA. La zona con el índice de cobertura más bajo en este grupo es Suroeste con tan sólo un 2,01 \%, seguido de Campiña Sur (3,52 \%), La Siberia (4,12 \%), Zafra (4,20 \%), Montehermoso (4,27 \%) y por último, La Serena, con un índice de 4,73\% (la media extremeña es de 5,3). Éstas son las que presentan una peor situación en nuestra región, debido al fuerte envejecimiento que sufren y la escasa oferta residencial que prestan.

2. Zonas Sociosanitarias muy envejecidas y envejecidas con un alto grado de adecuación entre la oferta y la demanda en residencias geriátricas. Son espacios que padecen un fuerte envejecimiento demográfico y a la vez presentan una oferta en las residencias geriátricas suficiente para cubrir la posible demanda, por lo que su grado de adecuación entre la oferta y la demanda es adecuado. Este grupo está formado por seis zonas que se localizan esta vez en la provincia de Cáceres siendo Sierra de San Pedro con el índice más elevado del 8,86 \%, seguida de Campo Arañuelo-Los Ibores (8,57 \%), Trujillo (7,60 \%), Coria (6,02 \%), Miajadas-Las Villuercas (5,52 \%) y por último Plasencia con un índice de un $5,32 \%$. A pesar de que éstas padecen un fuerte envejecimiento, en la actualidad, las plazas que ofertan en las residencias superan la media regional por lo que se puede afirmar que dentro del panorama regional son las que presentan una mejor adecuación entre la oferta y la demanda.

3. Zonas Sociosanitarias en transición y menos envejecidas con un bajo grado de adecuación entre la oferta y la demanda en residencias. Son zonas que aún no padecen un fuerte envejecimiento demográfico 
y, además, presentan una mínima oferta de plazas en residencias geriátricas, que es insuficiente para cubrir la demanda, aunque tengan menor volumen de población envejecida, por lo que su grado de adecuación entre la oferta y la demanda es bajo. Este grupo está formado por cuatro áreas que se localizan en la provincia de Badajoz, concretamente en el oeste, se trata de Tierra de Barros II, que con un índice de 4,70\% es la zona con una cobertura residencial más aceptable, seguido de Badajoz (4,55 \%), Tierra de Barros I $(4,02 \%)$ y por último, la zona con un menor índice de cobertura, Vegas Bajas-Sierra de Alburquerque, que cuenta con tan sólo un 2,42 \%. Éstas no son tan problemáticas como las más envejecidas y con un bajo nivel de adecuación entre la oferta y la demanda -el primer grupo-, ya que en la actualidad a pesar de no alcanzar un índice de cobertura aceptable, tampoco están muy envejecidas, por lo que el porcentaje de población que no podrían acceder a este servicio no es tan elevado como en los casos anteriores.

4. Zonas Sociosanitarias en transición y menos envejecidas con un alto grado de adecuación entre la oferta y la demanda en residencias. Se asemejan al grupo anterior, puesto que aún no padecen un fuerte envejecimiento demográfico y presentan una oferta en las residencias geriátricas suficiente para cubrir la posible demanda, por lo que su grado de adecuación entre la oferta y la demanda es alto. Este grupo está formado por cuatro zonas, de las cuales tres se localizan en la provincia de Badajoz: Vegas Altas, Mérida y Llanos de Olivenza, y la cuarta en la provincia de Cáceres, concretamente se trata de Cáceres. Ésta última alcanza el índice de cobertura residencial más alto de este grupo con un 7,91 \% y encabeza la lista de las zonas menos envejecidas y con una mejor adecuación entre su oferta y su demanda. Este índice sólo lo superan Sierra de San Pedro y Campo Arañuelo-Los Ibores, pero no hay que olvidar que se trata de territorios que padecen un fuerte envejecimiento. Vegas Altas es la segunda zona menos envejecida y con un índice de cobertura alto con un 6,82 \%, seguida de Mérida con un 6,03 \% y Llanos de Olivenza con un $5,50 \%$. Estas cuatro zonas son las que presentan la mejor situación regional, ya que el envejecimiento que sufren aún no es muy pronunciado y a la vez presentan una oferta residencial que puede hacer frente a una demanda soportable.

\section{ANÁLISIS DE LA OFERTA Y LA DEMANDA DE PLAZAS EN LOS CENTROS DE DÍA O UNIDADES DE ATENCIÓN DIURNA}

El otro bloque de servicios sociosanitarios que hemos analizado han sido los Centros o Unidades de Atención Diurna por Zonas Sociosanitarias. El total de centros de día ascendía a 105 en el año 2010, de los que 10 se ubicaban en la zona de La Siberia, convirtiéndose en la zona que ostenta el mayor número de centros de día, seguido por las zonas de Montehermoso, Campo Arañuelo-Los Ibores y Vegas Altas, con más de ocho centros. Siendo estas mismas zonas las que ofertan un mayor número de plazas en toda nuestra región, superior a la media regional situada en 115 plazas, destacando la zona de Montehermoso con 217 plazas (Figura 6).

Figura 6. Centro o Unidades de Atención Diurna y plazas por Zonas Sociosanitarias.

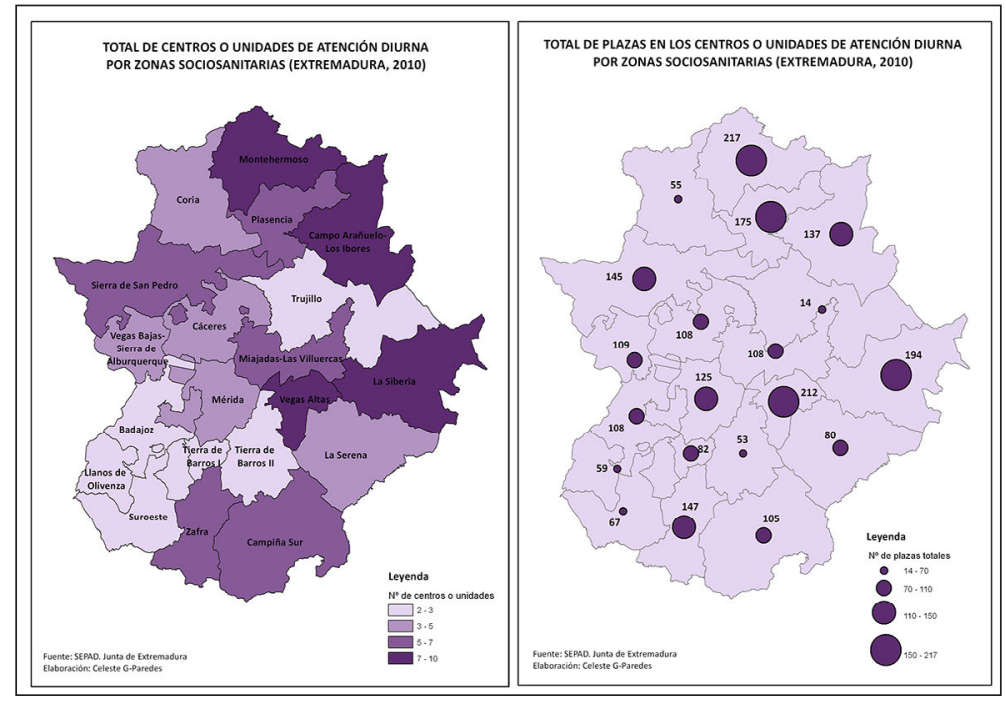

Fuente: SEPAD 
Siguiendo con la oferta de Centros de día, destacan Zafra, Plasencia, Sierra de San Pedro, Miajadas-Las Villuercas y Campiña Sur contando con una oferta de plazas que abarca entre los 150 y las 100 plazas. Una mayor disponibilidad de plazas en Centros de día, es un servicio muy valorado puesto que permite que las personas mayores continúen viviendo en la casa familiar, de tal forma que el nexo familiar continúa existiendo y es una forma de evitar el ingreso de la persona mayor en un centro geriátrico (Edwards, 2001; Espina, 2004). A la vez, permite un ahorro no sólo para las familias, puesto que es mucho más económico un centro de día que una residencia, sino también para la Administración siendo el objetivo primordial de esta la prestación de un servicio adecuado a las necesidades de la persona dependiente (Fernández-Mayoralas et al., 2003). Es decir, si una persona mayor aún es lo suficientemente autónoma para poder vivir en su casa, acudiendo a un centro de día si lo necesita, no tiene por qué ingresar en una residencia geriátrica, y se optimizan mejor los recursos tanto familiares como de la Administración en la atención a la dependencia.

Se detecta en la oferta de centros de día, el escaso número que albergan los territorios más habitados, como es el caso de Cáceres y Mérida con 4 centros de día, o Badajoz que siendo la de mayor población sólo tenía 3 centros. Aquellas que presentan un menor número de centros son Tierra de Barros I, Suroeste, Llanos de Olivenza y Trujillo, todas ubicadas en la provincia de Badajoz excepto Trujillo. Esto se refleja además en el número de plazas que se ofertan, donde Cáceres y Badajoz solamente presentan 108 plazas y Mérida 125. Estas tres zonas tienen prácticamente el mismo número de plazas que Campiña Sur y evidentemente el número de personas mayores es mucho más elevado en Cáceres y en Badajoz. Especial mención merece también Trujillo, que oferta tan solo 14 plazas, a pesar de tener municipios ubicados en Las Villuercas con un altísimo índice de envejecimiento.

Si se analiza la titularidad de los centros o unidades de día se observa la escasa existencia de oferta privada, sólo en siete de las veinte zonas existen centros de día privados. Destaca Badajoz donde no existe la oferta pública, los tres centros de día que alberga son privados (sus 180 plazas). En el lado opuesto se encuentran las áreas que solamente ofertan plazas en centros públicos como son Sierra de San Pedro, Coria, Montehermoso, Campo Arañuelo-Los Ibores y Trujillo, en la provincia de Cáceres; y La Siberia, La Serena, Campiña Sur, Tierra de Barros II, Suroeste, Llanos de Olivenza, Mérida y Vegas Bajas-Sierra de Alburquerque en la provincia de Badajoz (Figura 7).

En las únicas zonas donde encontramos un cierto equilibrio entre la oferta pública y la oferta privada en centros de día es en las Vegas Altas con 112 plazas privadas y 100 plazas públicas, Zafra con 82 plazas públicas y 65 privadas, Tierra de Barros I con 44 plazas públicas y 38 privadas y Tierra de Barros II con 33 plazas públicas y 20 privadas. Se aprecia como las iniciativas privadas son más abundantes en los municipios más desarrollados económicamente de la provincia de Badajoz, como es el eje Badajoz-Vegas Altas, con la excepción de Mérida, y el eje Almendralejo-Zafra. En la provincia de Cáceres, es la zona de Cáceres, con mayor desarrollo socioeconómico que otras áreas de la provincia, la que atrae un mayor número de inversiones privadas, seguido de aquellas que poseen un mayor volumen de población e ingresos como son Plasencia y Miajadas donde también se observa una incipiente presencia de la oferta privada (Figura 7).

Figura 7. Centro o Unidades de atención diurna por titularidad y plazas en las Zonas Sociosanitarias de Extremadura.

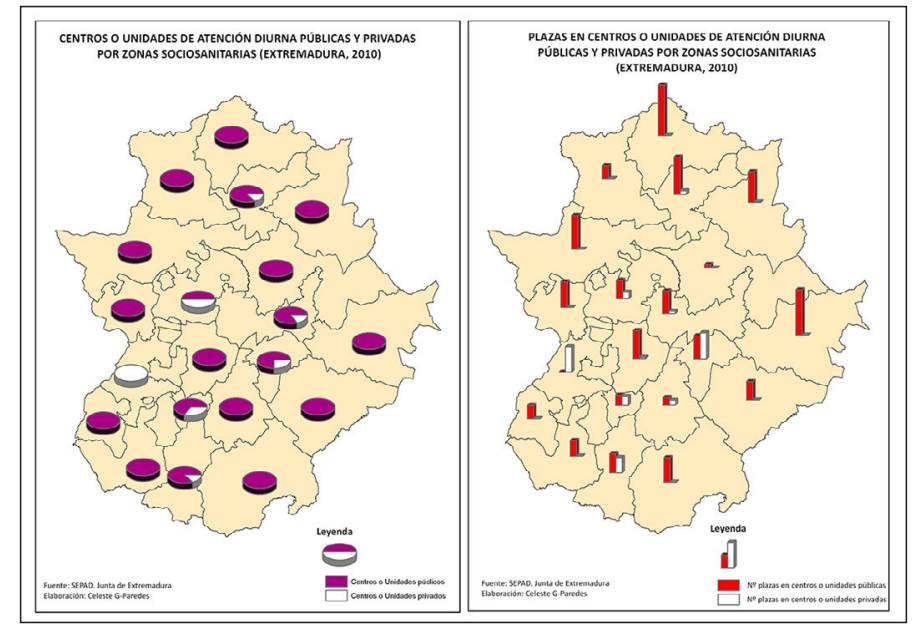

Fuente: SEPAD 
A pesar de registrar una escasa presencia del servicio de centros de día en algunas de las zonas de nuestra región, a nivel nacional ocupamos la tercera posición y estamos por encima de la media en cuanto a cobertura real en centros de día, relación entre el volumen de personas mayores de 65 años y número de plazas. Si la media se situaba en el 2009 en torno al 0,89 \% (Castellón et al., 2009), en Extremadura se superaba registrando un $1,1 \%$. Son nueve las áreas que están por encima de esta media regional, siendo La Siberia la que ostenta la primera posición en cuanto a cobertura en centros de día, con un 2,3\%, seguida de Vegas Altas y Montehermoso. Como en el análisis anterior, los territorios más poblados ocupan posiciones muy bajas, con índices demasiado escasos para el volumen de población mayor que registran, como es el caso de Badajoz con tan solo un índice de 0,54 \% y Tierra de Barros II con un 0,65. Queda evidente que la oferta en centros de día alcanza unas coberturas bajas para el volumen de población mayor que se contabiliza y en muchas de las zonas sociosanitarias, sería conveniente reforzar este servicio o reajustar la oferta en función de la demanda potencial real, sobre todo en Badajoz, donde además de existir poca oferta mayoritariamente es privada (Figura 8).

Figura 8. Cobertura en centros o unidades de atención diurna y Grado de Envejecimiento

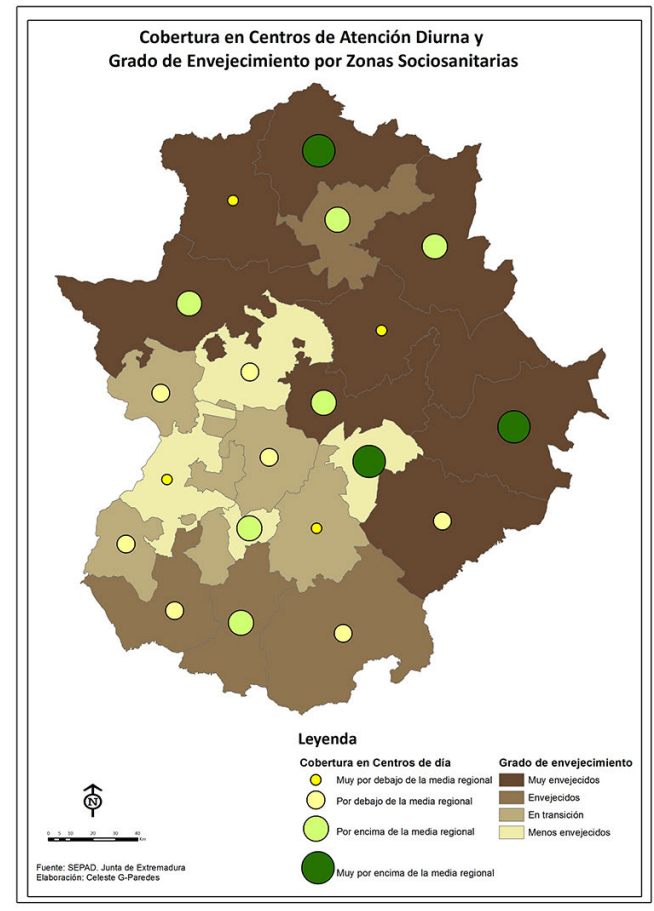

Fuente: SEPAD

Se ha empleado el mismo mapa del grado de envejecimiento de las Zonas Sociosanitarias utilizado en el análisis de la cobertura residencial, con las cuatro jerarquías ya determinadas: zonas muy envejecidas, envejecidas, en transición y menos envejecidas. El propósito de analizar esta variable con el Índice de Cobertura es obtener un "Nivel de adecuación" donde queden de manifiesto los territorios que en la actualidad poseen una aceptable o deficitaria adecuación entre su oferta y su demanda, teniendo como indicador básico el envejecimiento demográfico. Al realizar este análisis se han obtenido cuatro clases diferentes (Figura 9):

1. Zonas Sociosanitarias muy envejecidas y envejecidas con un bajo grado de adecuación entre la oferta y la demanda en centros o unidades de día. Destacan áreas que padecen un fuerte envejecimiento demográfico y a la vez presenta una oferta en los centros de día que no es suficiente para cubrir la posible demanda, por lo que su grado de adecuación entre la oferta y la demanda es bajo. Este grupo está formado por cinco zonas, tres pertenecen a la provincia de Badajoz: Campiña Sur, que registra el índice de cobertura en centros de día más alto de este grupo, pero no alcanza la media, con un 0,98\%; Suroeste con un índice de un 0,97 \% y La Serena con un índice de un 0,79\%. Las otras dos zonas se ubican en la provincia de Cáceres y alcanzan un bajísimo índice de cobertura residencial, se trata de Coria con un $0,47 \%$, pero sorprende aún más Trujillo con un ínfimo índice de un $0,18 \%$. Hay que reseñar que 
se trata de territorios envejecidos o muy envejecidos, con lo que el nivel de adecuación entre la oferta y la demanda es insuficiente.

Figura 9. Nivel de adecuación entre la oferta y la demanda en los centros o unidades de atención diurna por Zonas Sociosanitarias.

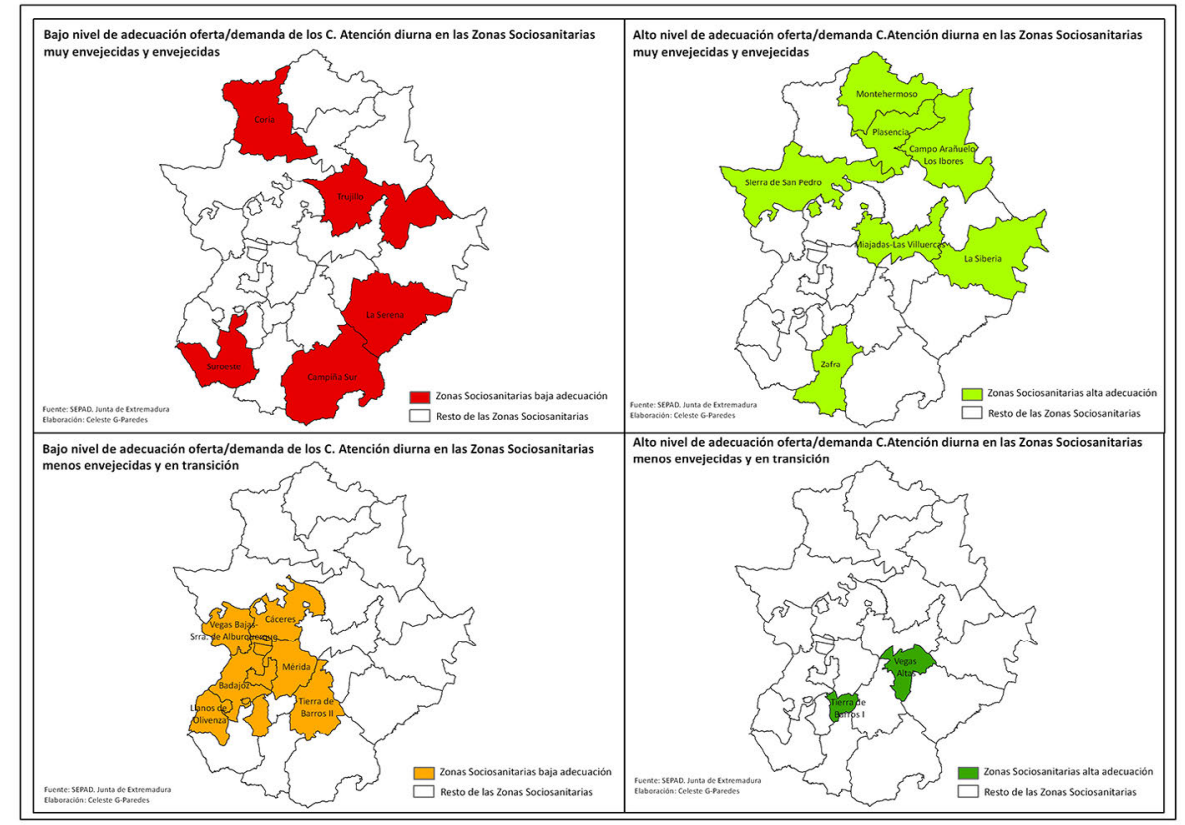

Fuente: SEPAD

2. Zonas Sociosanitarias muy envejecidas y envejecidas con un alto grado de adecuación entre la oferta y la demanda en centros o unidades de día. Son territorios que padecen un fuerte envejecimiento demográfico y presentan una oferta en los centros de día suficiente para cubrir la posible demanda, por lo que su grado de adecuación entre la oferta y la demanda es adecuado. Este grupo está conformado por siete zonas que se localizan en su mayoría en la provincia de Cáceres, concretamente cinco de las siete. El área que alcanzaba el mayor índice de cobertura en los centros de día es La Siberia, ubicada en la provincia de Badajoz, con un 2,37 \%, seguido por Montehermoso, Plasencia, Sierra de San Pedro, Campo Arañuelo-Los Ibores, Zafra y Miajadas-Las Villuercas, esta última con un 1,18\%. Éstas presentan las mejores condiciones de nuestra región en cuanto a la oferta en centros de día, pero sin embargo, la demanda es bastante elevada, ya que todas registran un grado de envejecimiento muy alto.

3. Zonas Sociosanitarias en transición y menos envejecidas con un bajo grado de adecuación entre la oferta y la demanda en centros o unidades de día. Son territorios que aunque no padecen un fuerte envejecimiento demográfico tampoco alcanzan una oferta en los centros de día suficiente para cubrir la posible demanda, por lo que su grado de adecuación entre la oferta y la demanda es bajo. Este grupo está formado por seis zonas, de las cuales cinco se ubican en la provincia de Badajoz, concretamente en el oeste de la provincia y la restante es la zona de Cáceres. Entre estas zonas nos encontramos a las más habitadas de la región como Badajoz, con un escaso índice de un 0,54 \%, Cáceres con un índice de un $0,82 \%$ y Mérida con un $1,02 \%$. De nuevo queda patente como las áreas más pobladas no presentan una oferta adecuada para cubrir las necesidades de las personas mayores en la atención en centros de día, aunque tengan menor grado de envejecimiento. En este grupo también destacan aquellas que cuentan con municipios demográficamente y económicamente más dinámicos como es el caso de Tierra de Barros II, Llanos de Olivenza y Vegas Bajas-Sierra de Alburquerque y registran un ínfimo índice de cobertura en centros de día.

4. Zonas Sociosanitarias en transición y menos envejecidas con un alto grado de adecuación entre la oferta y la demanda en centros o unidades de día. El resultado de esta consulta determina a las áreas que aún no padecen un fuerte envejecimiento demográfico y presentan una oferta suficiente para cubrir la posible demanda, por lo que su grado de adecuación entre la oferta y la demanda es alto. Este grupo está formado tan solo por dos zonas ubicadas ambas en la provincia de Badajoz, se trata de Vegas Altas con un 
índice de cobertura en centros de día de un 1,99 \% y Tierra de Barros I con un índice de 1,29 \%. Éstas son las que presentan las mejores condiciones de toda la región, ya que por un lado se trata de los territorios que aún muestran un cierto dinamismo demográfico y a la vez brindan una oferta de plazas en centros de día que está por encima de la media regional, con lo que se consigue un cierto equilibrio entre la oferta y la demanda en estos recursos sociosanitarios.

\section{SÍNTESIS DE RESULTADOS}

Este artículo se centra en el estudio de la distribución de dos recursos sociosanitarios -residencias geriátricas y centros de día- incluidos en el Catálogo del SAAD en la región de Extremadura. Se ha planteado el estudio en este ámbito geográfico porque estamos ante una región con un elevado sobreenvejecimiento -mayores de 80 años-, mucho más marcado sobre todo en las áreas más rurales, menos desarrolladas, peor comunicadas y que corresponden con las zonas montañosas de la provincia de Cáceres: Campo Arañuelo-Los Ibores, Trujillo, Coria, Miajadas-Las Villuercas, Montehermoso y Sierra de San Pedro; y en el este de la provincia de Badajoz: La Siberia y La Serena. Mientras que en las áreas urbanas y en el oeste de la provincia de Badajoz predominan las menos envejecidas, mejor comunicadas y con más elevados recursos económicos relacionados con un sector agrario más productivo, como son Vegas Altas y Tierra de Barros.

Extremadura presenta un índice de cobertura superior a la media nacional, tanto en residencias geriátricas -índice de cobertura de 5,3\% en el 2010, frente al 4,43\% nacional - como en centros de día -índice de cobertura de un $1,1 \%$ frente al 0,89 \% nacional-. A la vista de estos datos se podría afirmar que la implantación de estos recursos sociosanitarios en nuestra región es óptimo. Pero se han detectado ciertas divergencias en la distribución de los mismos en el territorio extremeño, que han quedado de manifiesto en este estudio, llegando a obtener finalmente unos resultados fructíferos.

Del análisis realizado en la distribución de plazas ofertadas en las residencias geriátricas son Cáceres, Campo Arañuelo-Los Ibores, Badajoz y Sierra de San Pedro las zonas con una mayor oferta de plazas en las residencias. Se señalan, además, dos tipologías de localización de residencias en estos territorios, en los núcleos urbanos como Cáceres y Badajoz que ofertan un gran número de plazas en grandes residencias y zonas como Sierra de San Pedro o Campo Arañuelo que se difuminan en un número elevado de pequeñas residencias ubicadas por todo su territorio. Las últimas posiciones las ocupan La Siberia, Tierra de Barros I, Vegas Bajas-Sierra de Alburquerque y Suroeste, donde además se encuentran el menor número de residencias. Por lo que presentan una tipología de pocas residencias, pequeñas y por ello con escasa oferta de plazas para estos territorios que además en el caso de La Siberia y Suroeste son las que alcanzan un alto grado de envejecimiento. Sin duda, una de las conclusiones extraídas más destacable es el predominio de la oferta pública frente a la privada en la atención residencial, de las 229 residencias geriátricas, un $67 \%$ ostentaban una titularidad pública frente a un escaso $33 \%$ de titularidad privada. Concentrándose además la oferta privada en las zonas más pobladas y dinámicas ubicadas en el oeste de la provincia de Badajoz. Donde la Administración Central ha apostado por la implantación de residencias públicas son Sierra de San Pedro, Coria, Montehermoso y Suroeste, que son justo las que registraban un mayor número de residencias geriátricas totales.

Las zonas donde se ha detectado una óptima adecuación entre la oferta y demanda de plazas en residencias geriátricas son las más envejecidas de la provincia de Cáceres, como son Sierra de San Pedro, Campo Arañuelo-Los Ibores, Trujillo, Coria y Las Villuercas. Dentro de este grupo también presentan un menor grado de envejecimiento Cáceres, Vegas Altas, Mérida y Los Llanos de Olivenza. Existe una clara diferenciación entre ambos grupos, si bien el primero pertenece a los territorios menos dinámicos tanto demográfica como económicamente -con alguna excepción de municipios con una entidad mayor como son Navalmoral de la Mata, Trujillo y Coria-, por el contrario en el último grupo se ubican la mayoría de los municipios más poblados de nuestra región -como son Cáceres, Don Benito, Villanueva de la Serena y Mérida-, siendo bastante importante el volumen de población mayor dependiente que cuenta con una oferta adecuada en su área.

Por otro lado, se señalan las zonas que presentan una peor situación en nuestra región debido al fuerte envejecimiento que sufren y la escasa oferta residencial que prestan, ubicándose mayoritariamente en la provincia de Badajoz, de este a oeste: La Siberia, La Serena, Campiña Sur, Zafra y Suroeste. Junto a ellas hay que añadir solamente Montehermoso, ubicada en la provincia de Cáceres. Dentro de este apartado, merecen especial interés los territorios que aún no padecen un fuerte envejecimiento demográfico pero tampoco prestan una oferta residencial suficiente, se localizan en el oeste de la provincia de Badajoz, en 
los municipios y comarcas donde predomina el regadío - Vegas Bajas y Altas del Guadiana- y su prolongación hacía Tierra de Barros. Ciudades muy pobladas como Badajoz presentan un modelo no adecuado a la realidad de su demanda, debido al elevado número de personas mayores que contabiliza, si bien es cierto que en la actualidad dispone de una red de centros públicos y privados, éstos no cuentan con una oferta suficiente. Una posible respuesta sería que zonas colindantes como los Llanos de Olivenza y Vegas Altas absorba la demanda excedentaria de esta ciudad.

En cuanto a las conclusiones extraídas de la distribución de los centros o unidades de atención diurna el primer dato revelador es que del total de los 105 centros existentes, 94 centros tienen una titularidad pública y solamente los 11 restantes poseen una titularidad privada. Lo que se traduce en una escasa presencia de la oferta privada en este recurso sociosanitario, de hecho del total de las 2.300 plazas que se ofertan, unas 1.894 plazas pertenecen a los centros públicos y 406 a los centros privados, lo que representa un $82 \%$ de oferta pública frente a un $18 \%$ de la oferta privada.

La peor situación con respecto al nivel de adecuación entre el grado de envejecimiento y la cobertura en centros de día la presentan tres áreas de la provincia de Badajoz como son Campiña Sur, Suroeste y La Serena; y dos zonas de la provincia de Cáceres: Coria y Trujillo. Las zonas que ostentan una oferta aceptable en centros de día, pero sin embargo, la demanda es bastante elevada ya que todas registran un alto grado de envejecimiento son siete: Montehermoso, Plasencia, Sierra de San Pedro, Campo Arañuelo-Los Ibores y Miajadas-Las Villuercas. Las más habitadas se encuadran en el grupo de las que aún no sufren un fuerte envejecimiento demográfico y a la vez no presentan una oferta suficiente en los centros, nos referimos a Badajoz, Cáceres y Mérida. De nuevo queda patente como los territorios más poblados no presentan una oferta adecuada para cubrir las necesidades de las personas mayores en la atención en centros de día. En este grupo también se enmarcan municipios demográficamente muy dinámicos como es el caso de Tierra de Barros II, Llanos de Olivenza y Vegas Bajas-Sierra de Alburquerque. Son sólo dos zonas las que muestran las mejores condiciones de toda nuestra región, son Vegas Altas y Tierra de Barros I, ambas ubicadas en la provincia de Badajoz.

Como propuesta se plantea reforzar la oferta de plazas en residencias sobre todo en las Zonas Sociosanitarias más envejecidas, que registran una cobertura residencial inferior a la media. Asimismo se propone incrementar ésta en aquellas áreas donde predomina la oferta privada, porque existe una posible demanda que no está siendo cubierta. Tras revisar el modelo actual de ubicación de residencias, queda de manifiesto que la Administración Central primero ha atendido a los territorios más envejecidos de nuestra región, que no son los más poblados, de ahí que exista ese desajuste entre la oferta pública y privada en todo el oeste de la provincia de Badajoz, demandando en la actualidad una mayor disponibilidad de plazas.

Atender las necesidades de todos los ciudadanos mayores extremeños es todo un reto para la Administración Central después de la aplicación de la conocida comúnmente como Ley de Dependencia. Puesto que nuestra región está caracterizada por la dispersión de su población y el elevado número de municipios menores que recorren todo nuestro territorio. El gran desafío que se plantea no pasa por la necesidad de crear nuevas residencias geriátricas donde en un futuro cercano verán incrementadas sus tasas de ingresos debido al fuerte envejecimiento que padecen nuestros municipios, si no pasa por una revisión muy pormenorizada del índice de cobertura residencial, incrementado dicho índice en aquellas zonas donde sea deficitario. El propósito es claro que todos los ciudadanos tengan derecho a una vejez digna vivan en la ciudad o en un municipio rural de montaña

\section{BIBLIOGRAFÍA}

ABELLÁN GARCÍA, A. (2000): "El envejecimiento demográfico en España: balance de un siglo", en Perfiles y Tendencias, vol. 1, pp. 6.

ABELLÁN GARCÍA, A. e HIDALGO CHECA, R.M. (2011): "Definiciones de discapacidad en España", en Informes Portal Mayores, junio, $\mathrm{n}^{\circ} 109$.

CACHÓN RODRÍGUEZ, L. (1992): "El envejecimiento de la población en Europa y las políticas comunitarias para las personas de edad avanzada", en Revista de Economía y Sociología del Trabajo, no 18, pp. 116-125.

CAMACHO, J.A., RODRÍGUEZ, M. y HERNÁNDEZ, M. (2008): "El sistema de atención a la dependencia en España: evaluación y comparación con otros países europeos", en Cuadernos Geográficos, no 42 , pp. 37-53. 
CASTEJÓN VILLAREJO, P. et al. (2009): "Los servicios sociales para las personas mayores de España", en Perfiles y Tendencias, $\mathrm{n}^{\circ} 43$, pp. 46.

CONSEJO DE EUROPA (1998): Recomendación No R. (98) 9 del Comité de Ministros a los Estados Miembros relativa a la dependencia. Comité de Ministros del Consejo de Europa, 18 de septiembre de 1998, 9 p.

CRESPO LÓPEZ, M. y LÓPEZ MARTÍNEZ, J. (2008): "Cuidadoras y cuidadores: el efecto del género en el cuidado no profesional de los mayores", en Perfiles y Tendencias, no 35, 36 p.

DÍAZ MARTÍN, R. y MADRIGAL MUÑOZ, A. (2007): "La atención a las personas mayores en situación de dependencia en su último período de vida", en Perfiles y Tendencias, no 28, 38 p.

EDWARDS, P. (2001): "Salud y envejecimiento. Un documento para el debate", en Perfiles y Tendencias, vol. 4 y 5,40 p.

EGEA GARCÍA, C. y SARABIA SÁNCHEZ, A. (2001): "Clasificaciones de la OMS sobre discapacidad", en Boletín del Real Patronato sobre Discapacidad, n 50, pp. 15-30.

EGEA GARCÍA, C. y SARABIA SÁNCHEZ, A (2003): Nuevos conceptos y terminología de la discapacidad en la CIF de la OMS. En VERDUGO ALONSO, M.A. y JORDÁN DE URRIES VEGA, F.B. (coords.): Investigación, innovación y cambio. Ed. Amarú. Salamanca, pp. 797-810.

ESPINA MONTERO, Á. (2004): "Estado del bienestar y teorema de la imposibilidad", en ICE, Revista de Economía, vol. 815, pp. 61-80.

FERNÁNDEZ-MAYORALAS FERNÁNDEZ, G., et al. (2003): "Envejecimiento y salud. Diez años de investigación en el CSIC", en Revista de Gerontología, vol. 13-1, pp. 43-46.

GARCÍA, C. y NIETO, A (2012): "La situación sociodemográfica actual en el medio rural de Extremadura”, en REQUES, P. y COS, O. (edit.): La población en clave territorial. Procesos, estructuras y perspectivas de análisis. Actas del XIII Congreso de la Población Española. Santander: Ministerio de Economía y Competitividad, Gobierno de Cantabria, Asociación de Geógrafos Españoles y Universidad de Cantabria, pp. 249-256.

GARCÍA, C. y NIETO, A. (2013): Distribución y localización de los servicios sociosanitarios en Extremadura: las residencias geriátricas. En: GUTIÉRREZ, J. A. et al. (Eds.). Los servicios: dinámicas, infraestructuras y cohesión territorial. Ed. Asociación de Geógrafos Españoles y Universidad de Extremadura. Cáceres, pp. 181-197.

GOBIERNO DE ESPAÑA (2006): Ley 39/2006, de 14 de diciembre, de Promoción de la Autonomía Personal y Atención a las personas en situación de dependencia. Boletín Oficial del Estado, 15 de diciembre 2006, no 299, 44 p. 142-44.156.

GOBIERNO DE ESPANA (2007): Real Decreto 504/2007, de 20 de abril, por el que se aprueba el baremo de la valoración de la situación de dependencia establecidos por la Ley 39/2006, de 14 de diciembre de promoción de la autonomía personal y atención a las personas en situación de dependencia. Boletín Oficial del Estado, 21 de abril de 2007, n 96, pp. 17.646-17.685

GOBIERNO DE ESPAÑA (2012): Resolución de 13 de julio de 2012, de la Secretaria de Estado de Servicios Sociales e Igualdad, por la que se publica el Acuerdo del Consejo Territorial del Sistema para la Autonomía y Atención a la Dependencia para la mejora del sistema del sistema para la autonomía y atención a la dependencia. Boletín Oficial del Estado, 03 de agosto de 2012, no 185, pp. 55.657- 55.674.

GOBIERNO DE EXTREMADURA (2011): Orden de 13 de Mayo de 2011, por la que se establece el catálogo de servicios y prestaciones económicas del Sistema del Sistema para la Autonomía y Atención a la Dependencia de la Comunidad Autónoma de Extremadura. Diario Oficial de Extremadura, 19 de mayo de 2011, no 95, pp. 12.504-12.524.

IMSERSO (2005): Atención a las Personas en Situación de Dependencia en España. Libro Blanco. Ed. Ministerio de Trabajo y Asuntos Sociales. Madrid, 820 p.

LEICHSENRING, K. (2005): "Proporcionar una asistencia sanitaria y social integrada a las personas mayores: perspectiva europea”, en Perfiles y Tendencias, nº15, 36 p.

MiNGUELA, M. A. (2010): "Atención a las personas potencialmente dependientes en Andalucía: una primera aproximación a las disparidades territoriales”, en Cuadernos Geográficos, n 46, pp. 209-231.

NIETO, A. y GURRÍA, J.L. (2008): "Las políticas rurales europeas y su impacto en Extremadura", en Boletín de la Asociación de Geógrafos Españoles, n48, pp.225-246.

NIETO, A. y GURRÍA, J.L. (2010): "El modelo rural y el impacto de los programas LEADER y PRODER en Extremadura (Propuesta metodológica)", en Scripta Nova, Revista Electrónica de Geografía y Ciencias Sociales, vol. XIV, nº 340. 
ORGANIZACIÓN MUNDIAL DE LA SALUD -OMS- (2001): Clasificación Internacional del Funcionamiento, de la Discapacidad y de la Salud. Ed. IMSERSO. Madrid, 258 p.

PUYOL ANTOLÍN, R; VINUESA A., J. y ABELLÁN GARCÍA, A. (1993): Los grandes problemas actuales de la población. Ed. Síntesis. Madrid, $235 \mathrm{p}$.

RODRÍGUEZ PRIETO, D. (2002): "La perspectiva local en los servicios para los mayores", en Revista Catalana de Sociología, no 16 , pp. 97-132.

RODRÍGUEZ RODRÍGUEZ, P. (2004): "Envejecimiento en el mundo rural: necesidades singulares, políticas específicas", en Perfiles y Tendencias, vol.11, 30 p.

ROJO PÉREZ, F. et al. (2007): "Entorno residencial de los mayores en España. Hacia una clasificación municipal", en Boletín de la AGE, no 43, pp. 51-72.

SÁNCHEZ FIERRO, J. (2004): Libro Verde sobre la Dependencia en España. Ed. Ergon. Madrid, 213 pp.

SERVICIO DE ESTADÍSTICAS DE LA SUBDIRECCIÓN GENERAL ADJUNTA DE VALORACIÓN, CALIDAD Y EVALUACIÓN -SAAD IMSERO- (2012): Estadísticas del Sistema para la Autonomía y la Atención a la Dependencia. Ed. IMSERSO. Madrid.

VINUESA, J. (1997): Demografía: análisis y proyecciones. Ed. Síntesis. Madrid, 366 p. 